\title{
A Conceptual Model for Integrating Transport Planning: MRP IV
}

\author{
Josefa Mula, Manuel Díaz-Madroñero, and David Peidro \\ Research Centre on Production Management and Engineering (CIGIP) \\ Universitat Politècnica de València, Escuela Politécnica Superior de Alcoy \\ Plaza Ferrándiz y Carbonell 2, 03801, Alcoy, Alicante, Spain \\ \{fmula, fcodiama, dapeipa\} @cigip.upv.es
}

\begin{abstract}
In this article, a conceptual model, called MRP IV, is proposed in order to serve as a reference to develop a new production technology that integrates material planning decisions, production resource capacities and supply chain transport for the purpose of avoiding the suboptimization of these plans which, today, are usually generated sequentially and independently. This article aim is twofold: (1) it identifies the advances and deficiencies in the MRP calculations, mainly based on the dynamic multi-level capacitated lot-sizing problem (MLCLSP); and (2) it proposes a conceptual model, defining the inputs, outputs, modeling and solution approaches, to overcome the deficiencies identified in current MRP systems and act as a baseline to propose resolution models and algorithms required to develop MRP IV as a decision-making system.
\end{abstract}

Keywords: MRP, integration, production planning, transport planning.

\section{Introduction}

Nowadays, the MRP (Material Requirement Planning) system, developed by Orlicky [1], continues to be the most widely used production planning system, despite the deficiencies identified in it. The evolutions of the MRP were reflected in the MRP II (Manufacturing Resource Planning) [2] system, which considers productive capacity constraints, MRP III (Money Resource Planning) [3], which introduces the financial function; and the MRP commercial evolution into the ERP (Enterprise Resource Planning) [4], which incorporates all the company functions into a unique decision system through modules whose central nucleus is the MRP. Later ERP systems developments have incorporated new information and communication technologies. Moreover, these have been adapted to the current economic context characterized by business globalization and the offshoring of suppliers by developing other functions such as supply chain management or transport, among others [5]. Original MRP systems were designed in the 70s as push systems in an environment where demand was greater than supply. Subsequently, and to adapt to new manufacturing environments where the supply was greater than demand pull systems appeared such as lean manufacturing and drum-buffer-rope. However, the inadequacy of push-based philosophy to today's environment characterized by high volatility and low demand, and the 
limited set of tools for materials planning and inventory control in pull systems, has led to the emergence of a new MRP, called Demand-Driven MRP (DDMRP) [6].

Many works exist in the academic literature that have attempted to overcome some of the deficiencies of traditional MRP such as results optimization, considering uncertainty in certain parameters, inflated lead times, etc. However in both the commercial and academic environments, the MRP and its variants focus on material requirements and on production capacity planning, which are the main disadvantages in supply chains where there is considerable offshoring of raw materials and parts suppliers. In these contexts, transport planning plays a leading role since high costs and logistical constraints usually make the proposed production plans suboptimal, and even infeasible, and manual replanning is a common practice in companies. This work aims to develop a new conceptual model, the MRP IV, which integrates the material, production resource capacities and transport planning (type of transport, form of collection, etc.) decisions in the supply chain to avoid the suboptimization of these plans which, nowadays, are usually generated sequentially and independently.

The rest of the paper is arranged as follows: Section 2 offers a literature review about MRP and production planning problems. Section 3 presents the MRP IV conceptual model. Finally, the last section provides conclusions and directions for further research.

\section{$2 \quad$ Literature Review}

In today's competitive environment, organizations need MRP systems to optimize their production planning decisions. Thus according to Yenisey [6], although the earlier MRP formulations were not associated with any form of optimization, aspects such as profit maximization and constraints related to supply, demand or available resources were gradually incorporated to optimize MRP problems. In this sense, the seminal works of Karni [7] and Billington et al. [8] who model MRP problems with mixed integer linear programming can be highlighted. Later, Yenisey [9] presents a flow network with a side constraints approach to optimize material flows in MRP problems. Noori et al. [10] develop a fuzzy multi-objective linear programming model to extend the work proposed by Yenisey [9] which considers the minimization of total costs and time. However, the premise of a completely deterministic scenario does not match the reality of a manufacturing environment. The literature reports different approaches to consider uncertainty in MRP systems, such as simulation [11], [12], stochastic inventory control [13], fuzzy logic [14], fuzzy mathematical programming [15-18], fuzzy programming with resources based on the credibility theory [19] and MRP parameterization [20-22], among others. Other approaches to consider uncertainty in MRP systems can be found in several reviews [23-25].

On the other hand, the importance of the bill of materials (BOM) in MRP systems is reflected in several works that redefine the traditional BOM concept to adapt MRP systems to new manufacturing environments. Chen et al. [26] adjust the traditional MRP approach for the make-to-order environment to consider customization features by generating a BOM for each customized product. Ram et al. [27] propose a flexible BOM to deal with possible shortages when using MRP to plan the requirements of 
dependent demand items. The requirements stated in the MPS (Master Production Schedule) are met in a timely manner by substituting items for one another should shortages arise. A linear programming model is used to minimize deviation from the default BOM when shortage occurs. Lin et al. [28] develop a single-period, multiperiod mathematical programming model to optimize the purchase quantity from suppliers, while they satisfy demand using specific characteristics from the TFT-LCD industry. These specific issues are based on the alternative bill of materials (ABOM), customer preference for $\mathrm{ABOM}$ and the purchase quantity ratio.

Standard MRP calculations are based on the dynamic multi-level capacitated lotsizing problem (MLCLSP). Capacitated lot-sizing problems have attracted the scientific community's attention in recent decades and several literature reviews like [29-31], among others, have been published. Moreover, Buschkühl et al. [32] discuss both different modeling approaches to the optimization of MLCLSP problems and different algorithmic solution approaches by classifying them into five groups: mathematical programming-based, Lagrangian heuristics, decomposition and aggregation approaches, metaheuristics and problem-specific greedy heuristics. Armentano et al. [33] use a branch-and-bound procedure, with a linear programming relaxation based on a network flow formulation. The efficiency of the branch-and-bound method can be increased by reformulating the mathematical model, and by redefining the corresponding decision variables [34-37] and/or by introducing valid inequalities [38-40]. Other solution approaches can be found in the literature such as fix-and-relax heuristics [41], [42], rounding heuristics [43], column generation [44] and Lagrangian relaxation [45], among others. On the other hand, according to Jans and Degraeve [46], several metaheuristics have been developed for extensions of the standard lot sizing problems for which no good special purpose algorithm exists and which are too difficult to solve with commercial integer optimization. Metaheuristic algorithms range from simple local search procedures to complex learning processes which can handle large and complex problems. Chen and Chu [45] develop a heuristic method based on the combination of Lagragian relaxation and local search. At each iteration, a feasible solution of the original problem is constructed from the solution of the relaxed problem. This feasible solution is further improved by a local search that changes the values of two setup variables at each time. Barbarosoglu and Özdamar [47] analyze the performance of a general purpose simulated annealing procedure in solving the dynamic MLCLSP with general product structures. The proposed neighbourhood transition schemes are based on relaxing different types of constraints, each of which defines a different solution space. Moreover, Özdamar and Barbarosoglu [48] propose a solution method by combining the capability of the Lagrangean relaxation to decompose the hard-to-solve problems into smaller subproblems and the intensive search capability of the simulated annealing. Berretta et al. [49] develop a heuristic which integrates simulated annealing components and tabu search for solving MLCLSP with general product structures, setup costs, setup times, and lead times. Karimi et al. [50] propose a tabu search heuristic which starts from an initial feasible solution. The resulting feasible solution is improved by adopting the corresponding set-up and set-up carry-over schedule and re-optimizing variable costs, by solving a minimun-cost network flow problem. Besides, Hung and Chien [51] compare the 
performance of the tabu search, simulated annealing and genetic algorithms to solve MLCLSP. Xie and Dong [52] propose a heuristic genetic algorithm for these problems in which the presentation technique encodes only the binary variables for the setup patterns but derives other decision variables by making use of the problemspecific knowledge. Moreover, Jung et al. [53] present a genetic algorithm for the integrated production planning problem considering manufacturing partners (suppliers). The proposed genetic algorithm with a unique chromosome structure, chromosome generation method and genetic operators, generates quite good solutions when compared to commercial solvers.

However, despite the development of sophisticated solution methods, according to Lee et al. [54], the majority of lot-sizing models have not considered any productioninventory problem with incorporated transportation activities. Nowadays, the issue of transportation scheduling for shipping products (or delivering orders) by proper shipping modes at the right time becomes significantly important in production (or distribution) management, or for import and export activities. Thus, Lee et al. [54] analyze a dynamic lot-sizing problem which contemplates the order size of multiple products and a single container type simultaneously. The objective of this study is to determine the production lot sizes and the transportation policy that minimize total costs by means of a heuristic algorithm. Garcia-Sabater et al. [55] present an MRP model that successfully integrates delivery and production processes in an automotive supply chain with a just-in-time environment. Moreover, Hwang [56] provides efficient solution procedures to solve lot-sizing problems with integrated production and transportation operations. Concave production costs and stepwise transportation costs are assumed to model the economies of scale in production with the effect of shipment consolidation on transportation. In relation to inbound logistics, Ertogral [57] incorporates transportation costs into a multi-item, lot-sizing problem as a piecewise linear function of the amount transported. A Lagrangean decomposition-based solution procedure is suggested to compare the proposed model in different scenarios. Sancak and Salman [58] propose a multi-item, lot-sizing, mixed-integer mathematical programming approach to determine the number of items to order and how many trucks to use in a stochastic environment for the purpose of minimizing total inventory holding and transportation costs. However, neither case contemplates production planning.

\section{MRP IV: A Conceptual Model}

Today there is a large number of firms with offshore suppliers. The production planning systems they use do not simultaneously consider aspects relating to the transport of parts and raw materials to their installations. The most habitual procedure is MPS calculation and MRP, used to determine the quantities of each finished good to be produced in a given planning horizon, as well as the requirements of the associated parts and raw materials. Corresponding orders are firmly placed if the quantities to be ordered to suppliers can be transported via an existing transport network. Should the results obtained with MRP be infeasible as regards the transport network, the results obtained with MRP need to be manually amended until they are feasible, or it is necessary to increase the existing transport capacity and to rerun MRP. In this case, 
transport decisions are based on the commitment between covering demand, available occupation and the inventories of parts and raw materials. Generally in this context, transport planning is done manually with the help of spreadsheets, and is based on planners' experience and personal judgments; this situation generally implies obtaining suboptimum results.

This article proposes a conceptual model, called MRP IV, for production planning which integrates those aspects relating to provisioning transport. For this purpose, MRP IV contemplates various inputs (which could be considered in generic MRP and provisioning transport planning models) that generate different outputs to achieve one objective or several objectives. Figure 1 illustrates the proposed model. The left-hand side of Figure 1 includes the input parameters associated with production planning systems or MRP, while the right-hand side shows those relating to transport decisionmaking processes. Those parameters which can be used simultaneously for aspects relating to both production and transport planning are presented as elongated rectangles overlapping both areas. The MRP IV inputs, outputs, modelling and solution approaches are described below:

\section{Inputs}

1. Planning horizon with an equivalent extension to the suppliers' maximum lead time. The planning horizon is divided into equal periods, for instance, of a daily duration

2. Customer demand of the finished goods to be produced

3. BOM

4. Initial inventory and initial delayed demand of finished goods, parts and raw materials

5. Safety stocks of each finished good, part and raw material

6. The supply lead time of each part and raw material as it is considered null for finished goods. The lead time for parts and raw materials comprises the supplier production time, the transport time and the safety time.

7. Programmed receptions for each part and raw materials

8. Production system function costs. These are variable production costs, inventory holding costs, delayed demand costs, undertime hour costs of productive resources, overtime hour costs of productive resources and subcontracting costs

9. Production capacity of available productive resources

10. Production time. This is the time required to produce each product with the available productive resources

11. Setup time. It represents the capacity lost due to cleaning, machine adjustments, calibration, inspection, change in tooling, etc., when production for a new product starts

12. Production batch size

13. Parts and raw materials dimensions

14. Order lot size of each part and raw material. The quantities to order are multiple integers of this lot size. It may, or may not, coincide with the production lot size because, occasionally, the supplier can arbitrarily fix an order lot size in accordance with its preferences 
15. Transport suppliers function costs. These are costs that are fixed per vehicle employed, variable costs according to occupied volume, discounts, costs for using extra transport capacity, costs incurred by urgent deliveries, waiting truck costs, etc.

16. Transport capacity. This corresponds to the capacity of the transport network between the suppliers of parts and raw materials and the manufacturer of finished goods. This transport network is generally stable and is regulated by contracts drawn up between the manufacturer receiving parts and raw materials and the logistics or transport suppliers

17. Shipment modes. Different shipment modes can be considered depending on the order size of parts and raw materials and the suppliers' geographic location. For instance, full-truckload (FTL) for those suppliers with whom large-sized orders are placed; less-than-truckload (LTL) for those suppliers with whom smallersized orders are placed; milk-run for those suppliers close by to whom smallsized orders are sent, which are delivered on a vehicle occupied by orders frequently received from several similar suppliers. Shipment modes can also be regulated by means of contracts drawn by with transport suppliers

18. Shipment frequency. This consists in the frequency of parts and raw materials arriving from different suppliers. Frequency of arrival can also be fixed by drawing contracts between the manufacturer of finished goods and its transport suppliers

19. Shipping units. They are required for transporting parts and raw materials; for example, special containers, racks, pallets, etc.

\section{Modelling Approach}

Different modelling approaches, such as linear programming, (mixed) integer programming, multiobjective programming, fuzzy programming, stochastic programming or simulation/hybrid models can be considered to develop an analytical model which would represent MRP IV. This model will be composed of several constraints and one or several objectives such as minimizing total production, inventory, delayed demand, overtime, undertime, subcontracting and transport costs.

\section{Solution Approach}

Buschkühl et al. [32] identify five groups of solution approaches to solve lot sizing problems:

1. Mathematical programming

2. Lagrangian heuristics

3. Decomposition and aggregation heuristics

4. Metaheuristics

5. Problem-specific greedy heuristics. 


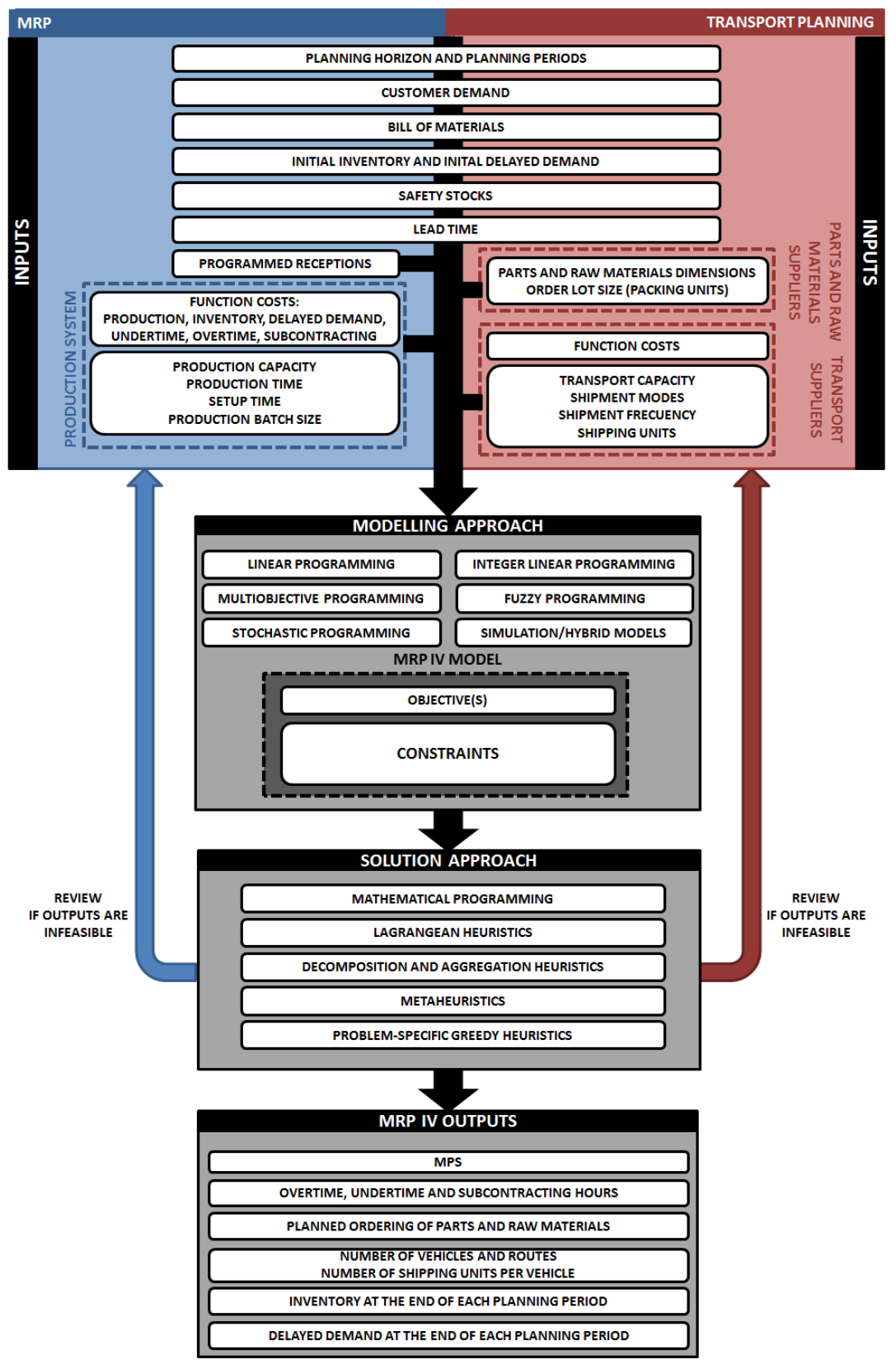

Fig. 1. MRP IV inputs, outputs, objectives, modeling and solution approaches 


\section{Outputs}

1. MPS, which specifies the quantity to produce of each finished good

2. Overtime and undertime hours of productive resources and subcontracting hours

3. Planned ordering of raw materials and parts, which specifies the quantities to order of each part or raw material to each supplier

4. Number of vehicles and routes and number of shipping units per vehicle. The number of vehicles employed is obtained for each shipping mode, as is the number of shipping units that each vehicle transports. Likewise for the milk-run shipping mode, the route to be followed by each vehicle to reach the manufacturer of finished goods is also determined

5. Inventory at the end of each planning period

6. Delayed demand at the end of each planning period.

After obtaining the outputs for the MRP IV model, their feasibility has to be evaluated. If outputs are infeasible, this may be due to causes relating to the production or transport system design. Therefore when outputs are infeasible, it is necessary to especially examine production and transport capacities, and to adjust them suitably before rerunning the MRP IV. Moreover, if outputs are feasible, it is necessary to economically evaluate the solution obtained by bearing in mind the different costs associated with the model. Although this situation can lead to obtaining a feasible solution for the MRP IV model, truck occupation may diminish and some vehicles have available space, which might involve an inappropriate cost. Therefore, it is necessary to reach a compromise solution that enables better truck occupation and maintains acceptable inventory levels. Similarly, the MRP IV model should include a period that reviews the transport network and the production system so that it can adapt to the various changes taking place in the environment.

\section{Conclusions}

This paper has reviewed the main advances and deficiencies of MRP systems, one of which is sequential provisioning transport and production planning decision-making processes. In order to address this, we propose a conceptual model, the MRP IV, which acts as a reference to develop a new production technology which integrates transport planning and MRP systems in the same decision-making system. The main inputs, objectives and outputs of the MRP IV model have been identified. A forthcoming work is related to the modeling and solution approaches for the proposed conceptual model, MRP IV.

Acknowledgment. This work has been funded by the Spanish Ministry of Science and Innovation project: 'Production technology based on the feedback from production, transport and unload planning and the redesign of warehouses decisions in the supply chain' (REVOLUTION) (Ref. DPI2010-19977). 


\section{References}

1. Orlicky, J.: Material Requirements Planning. McGraw-Hill, New York (1975)

2. White, O.W.: MRP II-Unlocking America's Productivity Potential. CBI Publishing, Boston (1981)

3. Schollaert, F.: Money resource planning, MRP-III: the ultimate marriage between business logistics and financial management information systems. Library Albert (1994)

4. Wylie, L.: ERP: A vision of the next-generation MRP II. Computer Integrated Manufacturing 300(339.2), 1-5 (1990)

5. Stadtler, H., Kilger, C.: Supply chain management and advanced planning: concepts, models, software and case studies. Springer, Berlin (2008)

6. Ptak, C., Smith, C.: Orlicky's Material Requirements Planning 3/E. McGraw-Hill Professional (2011)

7. Karni, R.: Integer linear programming formulation of the material requirements planning problem. Journal of Optimization Theory and Applications 35(2), 217-230 (1981)

8. Billington, P.J., McClain, J.O., Thomas, L.J.: Mathematical programming approaches to capacity-constrained MRP systems: review, formulation and problem reduction. Management Science, 1126-1141 (1983)

9. Yenisey, M.M.: A flow-network approach for equilibrium of material requirements planning. International Journal of Production Economics 102(2), 317-332 (2006)

10. Noori, S., Feylizadeh, M.R., Bagherpour, M., Zorriassatine, F., Parkin, R.M.: Optimization of material requirement planning by fuzzy multi-objective linear programming. Proceedings of the Institution of Mechanical Engineers, Part B: Journal of Engineering Manufacture 222(7), 887-900 (2008)

11. Tavakoli-Moghaddam, R., Bagherpour, M., Noora, A.A., Sassani, F.: Application of fuzzy lead time to a material requirement planning system. In: Proceedings of the 8th Conference on 8th WSEAS International Conference on Fuzzy Systems, vol. 8, pp. 208-213 (2007)

12. Sun, L., Heragu, S.S., Chen, L., Spearman, M.L.: Simulation analysis of a multi-item MRP system based on factorial design. In: Proceedings of the 2009 Winter Simulation Conference (WSC), pp. 2107-2114 (2009)

13. Inderfurth, K.: How to protect against demand and yield risks in MRP systems. International Journal of Production Economics 121(2), 474-481 (2009)

14. Barba-Gutiérrez, Y., Adenso-Díaz, B.: Reverse MRP under uncertain and imprecise demand. The International Journal of Advanced Manufacturing Technology 40(3), 413-424 (2009)

15. Mula, J., Poler, R., Garcia, J.P.: MRP with flexible constraints: A fuzzy mathematical programming approach. Fuzzy Sets and Systems 157(1), 74-97 (2006)

16. Mula, J., Poler, R., Garcia-Sabater, J.P.: Material Requirement Planning with fuzzy constraints and fuzzy coefficients. Fuzzy Sets and Systems 158(7), 783-793 (2007)

17. Mula, J., Poler, R., Garcia-Sabater, J.P.: Capacity and material requirement planning modelling by comparing deterministic and fuzzy models. International Journal of Production Research 46(20), 5589-5606 (2008)

18. Mula, J., Poler, R.: Fuzzy Material Requirement Planning. In: Kahraman, C., Yavuz, M. (eds.) Production Engineering and Management under Fuzziness. STUDFUZZ, vol. 252, pp. 39-57. Springer, Heidelberg (2010) 
19. Li, T., Lin, P., Sun, G.J., Liu, H.H.: Application of Fuzzy Programming with Recourse in Material Requirement Planning Problem. In: International Conference on Measuring Technology and Mechatronics Automation, ICMTMA 2009, vol. 2, pp. 546-549 (2009)

20. Hnaien, F., Dolgui, A., Ould Louly, M.A.: Planned lead time optimization in material requirement planning environment for multilevel production systems. Journal of Systems Science and Systems Engineering 17(2), 132-155 (2008)

21. Louly, M.A., Dolgui, A., Hnaien, F.: Optimal supply planning in MRP environments for assembly systems with random component procurement times. International Journal of Production Research 46(19), 5441-5467 (2008)

22. Louly, M.A., Dolgui, A.: Optimal time phasing and periodicity for MRP with POQ policy. International Journal of Production Economics 131(1), 76-86 (2011)

23. Mula, J., Poler, R., Garcia-Sabater, J.P., Lario, F.C.: Models for production planning under uncertainty: A review. International Journal of Production Economics 103(1), 271-285 (2006)

24. Dolgui, A., Prodhon, C.: Supply planning under uncertainties in MRP environments: A state of the art. Annual Reviews in Control 31(2), 269-279 (2007)

25. Wazed, M., Ahmed, S., Nukman, Y.: A review of manufacturing resources planning models under different uncertainties: state-of-the-art and future directions (2010)

26. Chen, Y., Miao, W.M., Lin, Z.Q., Chen, G.L.: Adjusting MRP for dynamic differen-tiation of identical items for process customisation. Production Planning and Control 19(6), 616626 (2008)

27. Ram, B., Naghshineh-Pour, M.R., Yu, X.: Material requirements planning with flexible bills-of-material. International Journal of Production Research 44(2), 399-415 (2006)

28. Lin, J.T., Chen, T.L., Lin, Y.T.: Critical material planning for TFT-LCD production industry. International Journal of Production Economics 122(2), 639-655 (2009)

29. Karimi, B., Fatemi Ghomi, S.M.T., Wilson, J.M.: The capacitated lot sizing problem: a review of models and algorithms. Omega 31(5), 365-378 (2003)

30. Jans, R., Degraeve, Z.: Modeling industrial lot sizing problems: a review. International Journal of Production Research 46(6), 1619-1643 (2008)

31. Quadt, D., Kuhn, H.: Capacitated lot-sizing with extensions: a review. 4OR: A Quarterly Journal of Operations Research 6(1), 61-83 (2008)

32. Buschkühl, L., Sahling, F., Helber, S., Tempelmeier, H.: Dynamic capacitated lot-sizing problems: a classification and review of solution approaches. OR Spectrum 32(2), 231$261(2010)$

33. Armentano, V.A., França, P.M., de Toledo, F.M.B.: A network flow model for the capacitated lot-sizing problem. Omega 27(2), 275-284 (1999)

34. Tempelmeier, H., Helber, S.: A heuristic for dynamic multi-item multi-level capacitated lotsizing for general product structures. European Journal of Operational Research 75(2), 296-311 (1994)

35. Stadtler, H.: Mixed integer programming model formulations for dynamic multi-item multi-level capacitated lotsizing. European Journal of Operational Research 94(3), 561-581 (1996)

36. Stadtler, H.: Reformulations of the shortest route model for dynamic multi-item multi-level capacitated lotsizing. OR Spectrum 19(2), 87-96 (1997)

37. Denizel, M., Altekin, F.T., Süral, H., Stadtler, H.: Equivalence of the LP relaxations of two strong formulations for the capacitated lot-sizing problem with setup times. OR Spectrum 30(4), 773-785 (2008) 
38. Belvaux, G., Wolsey, L.A.: Modelling practical lot-sizing problems as mixed-integer programs. Management Science, 993-1007 (2001)

39. Suerie, C.: Modeling of period overlapping setup times. European Journal of Operational Research 174(2), 874-886 (2006)

40. Absi, N., Kedad-Sidhoum, S.: The multi-item capacitated lot-sizing problem with setup times and shortage costs. European Journal of Operational Research 185(3), 1351-1374 (2008)

41. Suerie, C., Stadtler, H.: The capacitated lot-sizing problem with linked lot sizes. Management Science, 1039-1054 (2003)

42. Federgruen, A., Meissner, J., Tzur, M.: Progressive interval heuristics for multi-item capacitated lot sizing problems. Operations Research 55(3), 490 (2007)

43. Akartunalı, K., Miller, A.J.: A heuristic approach for big bucket multi-level production planning problems. European Journal of Operational Research 193(2), 396-411 (2009)

44. Degraeve, Z., Jans, R.: A new Dantzig-Wolfe reformulation and branch-and-price algorithm for the capacitated lot-sizing problem with setup times. Operations Research 55(5), 909-920 (2007)

45. Chen, H., Chu, C.: A Lagrangian relaxation approach for supply chain planning with order/setup costs and capacity constraints. Journal of Systems Science and Systems Engineering 12(1), 98-110 (2003)

46. Jans, R., Degraeve, Z.: Meta-heuristics for dynamic lot sizing: A review and comparison of solution approaches. European Journal of Operational Research 177(3), 1855-1875 (2007)

47. Barbarosoglu, G., Özdamar, L.: Analysis of solution space-dependent performance of simulated annealing: the case of the multi-level capacitated lot sizing problem. Computers \& Operations Research 27(9), 895-903 (2000)

48. Özdamar, L., Barbarosoglu, G.: An integrated Lagrangean relaxation-simulated annealing approach to the multi-level multi-item capacitated lot sizing problem. International Journal of Production Economics 68(3), 319-331 (2000)

49. Berretta, R., Franca, P.M., Armentano, V.A.: Metaheuristic approaches for the multi-level resource-constrained lot-sizing problem with setup and lead times. Asia-Pacific Journal of Operational Research 22(2), 261-286 (2005)

50. Karimi, B., Ghomi, S.M.T.F., Wilson, J.M.: A tabu search heuristic for solving the CLSP with backlogging and set-up carry-over. Journal of the Operational Research Society (March 2005)

51. Hung, Y.-F., Chien, K.-L., et al.: A multi-class multi-level capacitated lot sizing model (November 2000)

52. Xie, J., Dong, J.: Heuristic genetic algorithms for general capacitated lot-sizing problems. Computers \& Mathematics with Applications 44(1-2), 263-276 (2002)

53. Jung, H., Song, I., Jeong, B.: Genetic algorithm-based integrated production planning considering manufacturing partners. The International Journal of Advanced Manufacturing Technology 32(5), 547-556 (2007)

54. Lee, W.S., Han, J.H., Cho, S.J.: A heuristic algorithm for a multi-product dynamic lotsizing and shipping problem. International Journal of Production Economics 98(2), 204214 (2005)

55. Garcia-Sabater, J.P., Maheut, J., Garcia-Sabater, J.J.: A capacitated material require-ments planning model considering delivery constraints: A case study from the automotive industry. In: International Conference on Computers \& Industrial Engineering, CIE 2009, pp. 378-383 (2009) 
56. Hwang, H.C.: Economic lot-sizing for integrated production and transportation. Operations Research 58(2), 428-444 (2010)

57. Ertogral, K.: Multi-item single source ordering problem with transportation cost: A Lagrangian decomposition approach. European Journal of Operational Research 191(1), 156165 (2008)

58. Sancak, E., Sibel Salman, F.: Multi-item dynamic lot-sizing with delayed transportation policy. International Journal of Production Economics (2011) 